\title{
Effect of Electrolyte Addition on the Colloidal Stability of Aqueous Zeolite Sols
}

\author{
by Torsten Mäurer and Bettina Kraushaar-Czarnetzki*1)
}

Institute of Chemical Process Engineering CVT, University of Karlsruhe (TH), D-76128 Karlsruhe

Dedicated to Professor André M. Braun on the occasion of his 60th birthday

\begin{abstract}
Recovery of zeolites from aqueous media can be a very difficult operation, when the crystals have colloidal dimensions. The solid-liquid separation can be facilitated by processing at the respective isoelectric point (IEP) where the sol is unstable and the crystals form aggregates. The addition of salts results in a further improvement, because the zeolite agglomerates become larger, and the $\mathrm{pH}$ range of flocculation is broadened. This wider operational window, in particular, is of importance for the recovery of zeolites that would dealuminate or collapse at their respective IEP.
\end{abstract}

Introduction. - Handling of aqueous sols or suspensions of zeolite crystals is a frequently recurring operation in the manufacturing of zeolite-based catalysts or adsorbents. Starting with the zeolite synthesis in aqueous medium, the typical workup comprises repeated ion exchange in aqueous solutions and, finally, a wet shaping process during which bodies of suitable size, shape, strength, pore texture, and site distribution must be formed. Large agglomerates of crystals are beneficial, when zeolites must be recovered from their mother liquor or from ion-exchange solutions, whereas isolated zeolite single crystals, dispersed in the porous matrix of a shaped particle, are highly desirable when catalytic properties are to be optimized. These opposing requirements for efficient solid-liquid separations, on one hand, and optimum product quality, on the other hand, demand for means to control the particle size in a reversible manner.

It is well-known that the stability of particles with respect to aggregation depends on the balance between attractive London-Van der Waals and repulsive electrostatic forces. The magnitude of the electrostatic repulsion as a function of the distance from the particle surface can be influenced. It depends on the ionic strength in the diffusive layer and on the surface potential (Nernst potential), which, in turn, can be altered by adjusting the $\mathrm{pH}$ value. While the Nernst potential is not experimentally accessible, the electrokinetic potential at the shear plane, the zeta $(\zeta)$ potential, can be monitored. Dispersions can be regarded as stable, when the zeta potential is higher than $c a$. $|30 \mathrm{mV}|$, whereas the particles tend to form aggregates near the isoelectric point (IEP), which is defined as the $\mathrm{pH}$ at which the zeta potential is zero. The measurement of the zeta potential, therefore, is a widely used tool to characterize the stability of disperse systems. Electrokinetic data of numerous materials, in particular, of inorganics are documented in the literature.

1) Phone: +49-721-6083947/4133, fax: +49-721-6086118, e-mail: Bettina. Kraushaar@ciw.uni-karlsruhe.de 
Surprisingly, this does not hold for zeolites, although these materials are of utmost industrial importance. To our knowledge, only two papers exist that report on the zeta potential of zeolites [1][2]. These studies involved only three different samples in total, exhibiting completely different properties. Because the family of zeolites comprises more than hundred crystal-structure types, each of which with different pore textures and, in addition, preparable in different chemical compositions and crystal morphologies, the results reported in [1] [2] are not sufficient to identify general trends. Aiming at a more systematic approach, we recently investigated how the zeta potentials and the corresponding aggregation and peptization behaviors of zeolite crystals are affected by the presence or absence of pore-filling templates, by the amount of framework aluminium, and by the crystal size. This study involved samples of MFI, *BEA, and OFF (IUPAC structure codes of zeolites ZSM-5, beta, and offretite [3]) suspended in aqueous solutions of low ionic strength [4]. One important result concerns the fact that the aggregation of zeolite crystals occurs in a narrow $\mathrm{pH}$ range near the respective IEP, which, in many cases, refers to extremely acidic conditions.

Here, we will report on the possibility to reduce the repulsive forces between zeolite crystals by increasing the ionic strength, i.e., by adding salts. As a result, flocculation is possible in a broader $\mathrm{pH}$ range, and the resulting agglomerates are much larger than in the absence of salts. The solid-liquid separation of zeolite crystals, which is a very difficult operation when the crystals have colloidal dimensions (i.e., diameters $\varnothing \leq$ $500 \mathrm{~nm})$, can be greatly facilitated.

Experimental. - The properties of the zeolite samples used for this study are summarized in Table 1. All samples exhibited excellent crystallinity as indicated by X-ray powder diffraction, and almost spherical shape as observed by means of scanning electron microscopy. Sample 1, a silicalite with a mean crystal diameter of $80 \mathrm{~nm}$, was synthesized according to a procedure described in the patent literature [5]. Sample 2 was a commercial sample of ZSM-5 obtained from Bayer AG. Sample 3 was provided by ExxonMobil Europe. Samples 1 and 3 were employed in the as-synthezised form, i.e., their pores were still filled with the template $\left(\operatorname{Pr}_{4} \mathrm{~N}^{+}, \mathrm{TPA}^{+}\right)$ions. Sample 2 was provided in the template-free form.

Table. Properties of the Zeolite Samples

\begin{tabular}{lllrll}
\hline Sample & Structure & Crystal size $[\mathrm{nm}]$ & Si/Al & State & IEP \\
\hline 1 & MFI & 650 & 39 & contains template $\mathrm{TPA}^{+}$ & 4.8 \\
2 & MFI & 500 & 50 & template-free & $(\approx 0)$ \\
3 & MFI & 80 & $>2000$ & contains template $\mathrm{TPA}^{+}$ & 5.8 \\
\hline
\end{tabular}

The measurements of the zeta potential and the mean particle size of the zeolite particles were performed on a Zeta Sizer 3000 (Malvern). The zeta-potential measurement is based on Doppler electrophoresis. It is a requirement of this technique that the sample must be stagnant. Under stagnant conditions, however, particles with diameters larger than ca. $1500 \mathrm{~nm}$ tend to precipitate and can no longer be detected. Therefore, the particle sizes of all samples were additionally inspected with a Master Sizer (Malvern). This instrument is equipped with a pump. The liquid is back-mixed, and all particles are kept in suspension. A detailed description of the sample preparation and the $\mathrm{pH}$ adjustment in the context of the zeta potential measurements has been given in [4].

In the base-case experiments, no electrolytes except for dil. aq. $\mathrm{HCl}$ and $\mathrm{NaOH}$ solns. to adjust the $\mathrm{pH}$ were added, and the resulting Debye-Hückel lengths varied between $c a .3 \mathrm{~nm}$ in the neutral $\mathrm{pH}$ range and $1 \mathrm{~nm}$ at $\mathrm{pH} \leq 3$ or $\mathrm{pH} \geq 10$. To study the effects of higher electrolyte concentrations, aq. ammonium formate or ammonium acetate solns. were added in amounts and concentrations suitable to obtain concentrations of 0.1 or $0.5 \mathrm{~mol} / \mathrm{dm}^{3}$, resp., in the final zeolite sol. 
Results and Discussion. - It was shown in a previous study that the IEP of silicalite, a zeolite of MFI structure containing no detectable amounts of aluminium, exhibits an IEP at $\mathrm{pH} c a$. 5.8. Increasing amounts of $\mathrm{Al}$ incorporated in the framework result in a shift of the IEP to lower $\mathrm{pH}$ values. In addition, a Donnan equilibrium can be established, if the pore system of the zeolite is accessible for anions. As a consequence, the IEP of zeolites with ion-exchange capacity is found at extremely low $\mathrm{pH}$ values [4]. The IEP values of the samples under investigation (Table) are in line with these previous results.

The zeta potentials of Sample 1 as a function of the $\mathrm{pH}$ value are depicted in Fig. 1 for situations with and without addition of $0.1 \mathrm{~mol} / \mathrm{dm}^{3}$ electrolyte. The data show that the presence of a salt, be it ammonium acetate or ammonium formate, results in an increase in the IEP, which, however, is not very pronounced. In contrast, salt addition has a strong effect on the mean size of the particles as shown in Fig. 2. In all cases, the zeolite crystals form aggregates when the zeta potential approaches $\xi=0 \mathrm{mV}$. In the presence of dissolved salts, however, these aggregates are much larger. It can also be seen that aggregation of the crystals is possible in a broader range of $\mathrm{pH}$ and, accordingly, of zeta potentials.

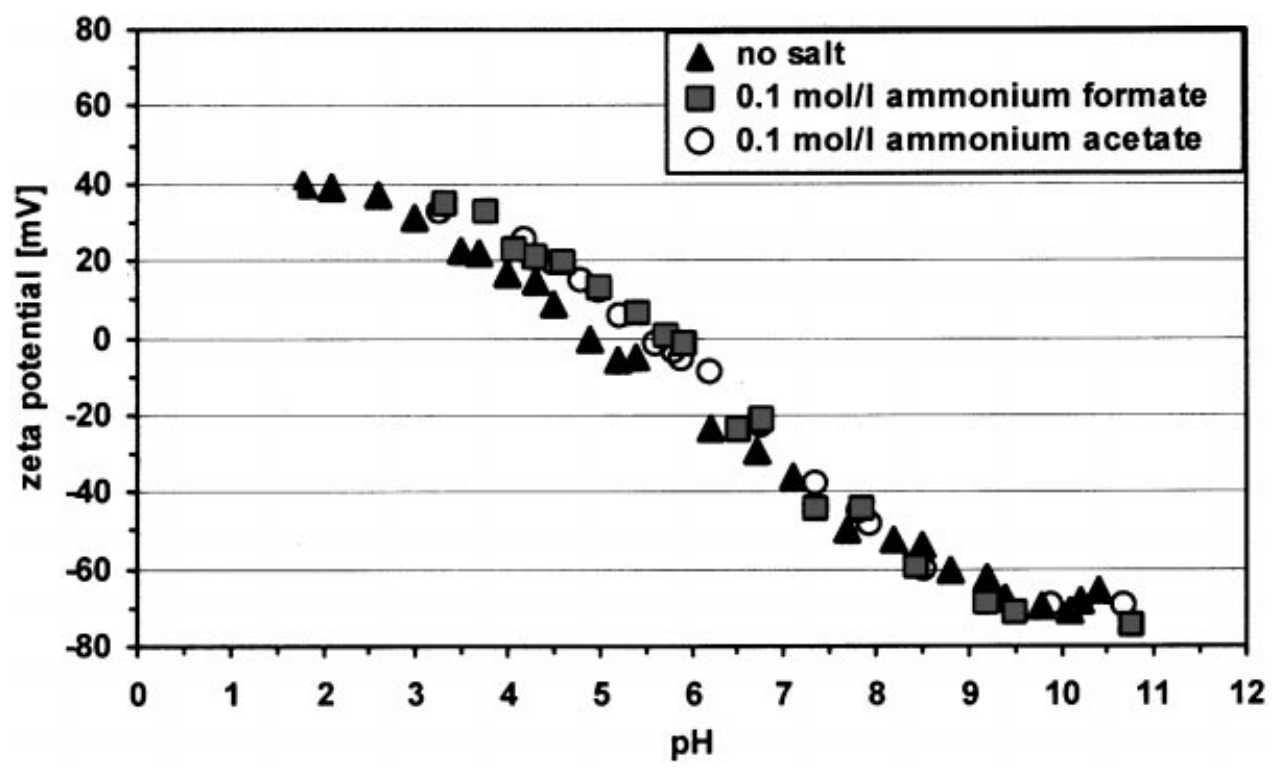

Fig. 1. Effect of $0.1 \mathrm{~mol} / \mathrm{l}$ ammonium formate or ammonium acetate on the zeta potentials of TPA-MFI (Sample $1, \mathrm{Si} / \mathrm{Al}=39$ ) as a function of the $\mathrm{pH}$

Of course, according to the well-known DLVO theory for electrostatic stabilization of colloidal particles, these effects are expected to be even more pronounced at salt concentrations higher than $0.1 \mathrm{~mol} / \mathrm{dm}^{3}$, because repulsive forces between particles strongly decrease with increasing ionic strength. The assessment of zeta potentials, however, is not reliable anymore when higher amounts of electrolyte are present.

To visualize the promoted aggregation of zeolite crystals at higher salt concentrations, we carried out simple sedimentation experiments and took photographs at 


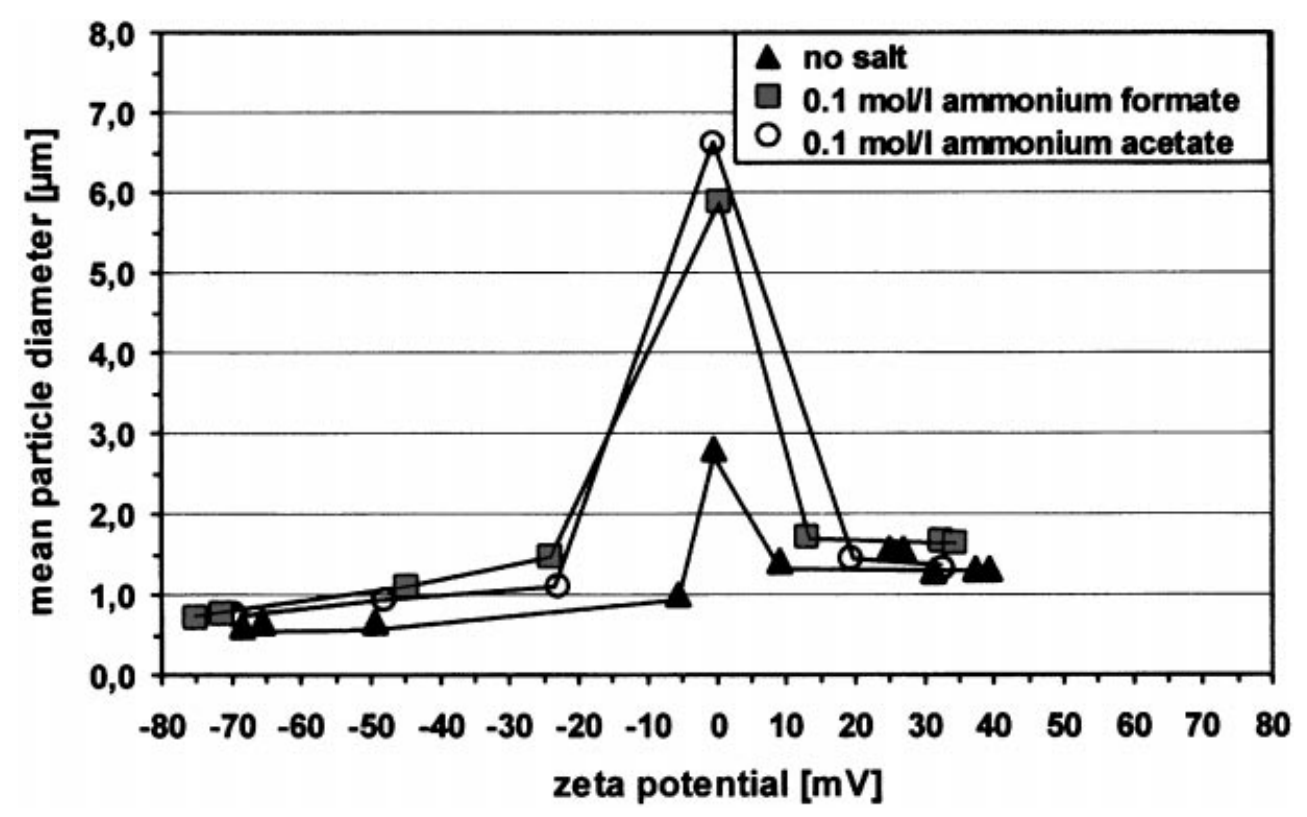

Fig. 2. Effect of $0.1 \mathrm{~mol} / \mathrm{l}$ ammonium formate or ammonium acetate on the mean particle size of TPA-MFI (Sample $1, \mathrm{Si} / \mathrm{Al}=39$ ) as a function of the zeta potential (see Fig. 1)

different points in time. Fig. 3 shows a series of pictures taken from a sol containing a template-free MFI zeolite (Sample 2). This zeolite is difficult to separate because the IEP is at $\mathrm{pH} \mathrm{ca}$. 0 , and the crystals usually remain monodisperse in the entire $\mathrm{pH}$ range above the IEP. The pictures in Fig. 3 show that the speed of the sedimentation is enhanced in an aqueous solution of $0.5 \mathrm{M}$ ammonium acetate. The addition of salt, in particular, allows for a faster recovery of the crystals under less acidic conditions, i.e., at $\mathrm{pH}$ 2.5. This is important because zeolites are unstable at low $\mathrm{pH}$ values. Aluminium is removed from the lattice. The structure collapses, if the resulting number of defects becomes too high. Highly siliceous zeolites, e.g., of MFI structure, are also dealuminated, but they can survive this treatment because the number of defects created is low [6]. In separate experiments (not shown), we observed that the $\xi$-potentials of MFI zeolites decreased during storage at $\mathrm{pH}<2$ due to dealumination of the framework. Therefore, we may assume that the IEP of Sample 2 shifted from $\mathrm{pH}$ of $c a .0$ to somewhat higher $\mathrm{pH}$ values during sedimentation at $\mathrm{pH} 1.5$. This would explain why Sample 2 precipitated relatively fast at $\mathrm{pH} 1.5$, even in the absence of ammonium acetate (Fig. 3, left sample).

A sedimentation experiment at almost neutral $\mathrm{pH}$ conditions is depicted in Fig. 4. The sample under investigation is a silicalite exhibiting an IEP at $\mathrm{pH} 5.8$. Usually, recovery of this zeolite sample is difficult, because the primary crystals are very small, exhibiting diameters of only $80 \mathrm{~nm}$. The photographs in Fig. 4 show that accelerated sedimentation without addition of a salt requires the exact adjustment of the $\mathrm{pH}$ to match the IEP (sample second left, $\mathrm{pH}$ 5.75). Both, at higher and lower $\mathrm{pH}$ values, the sedimentation is extremely slow. The presence of an electrolyte (Fig. 4, three samples 


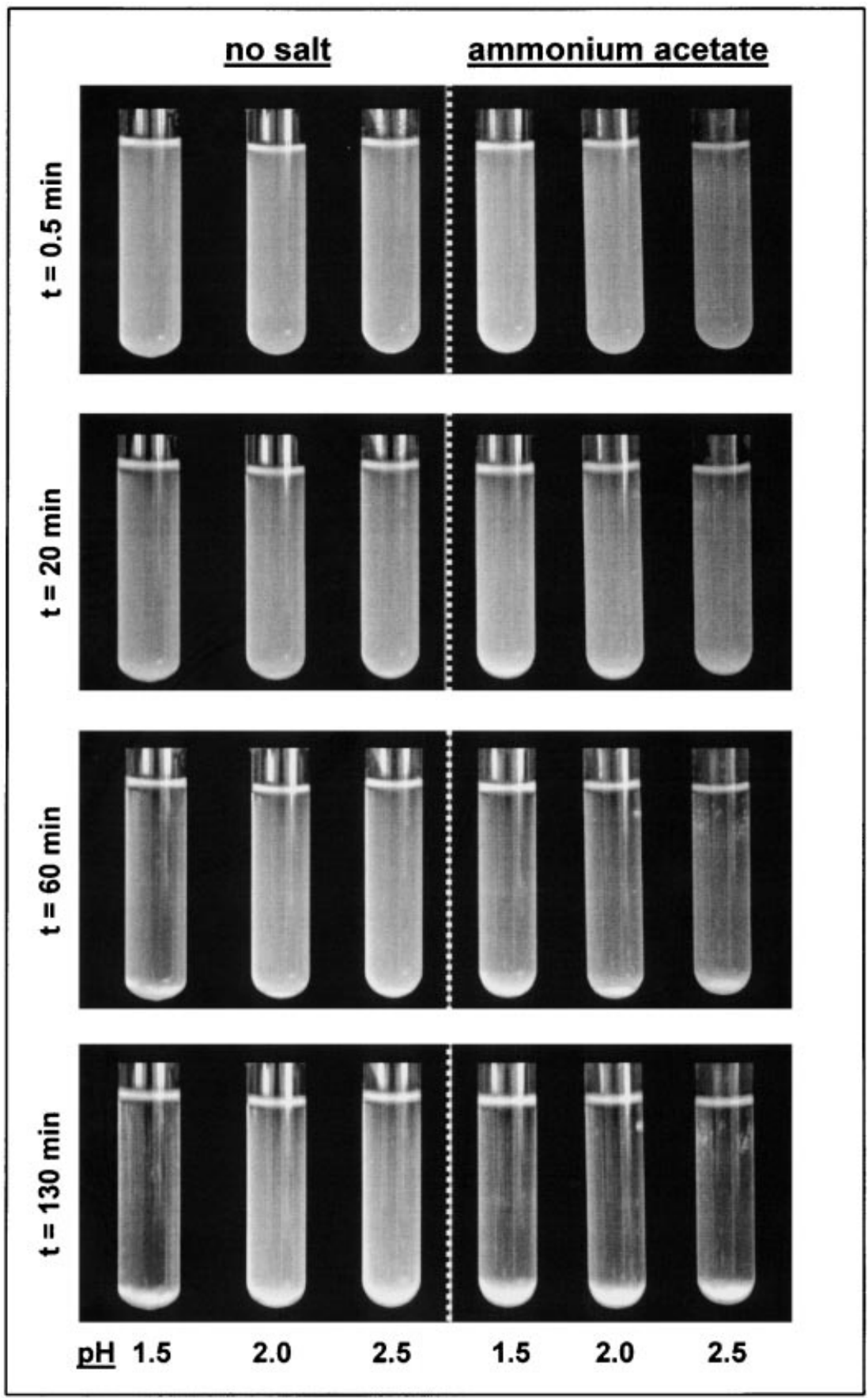

Fig. 3. Sedimentation of template-free $\mathrm{MFI}$ (Sample $2, \mathrm{Si} / \mathrm{Al}=50)$ suspended in $\mathrm{H}_{2} \mathrm{O}$ (left) and aqueous solution of $0.5 \mathrm{M}$ ammonium acetate (right) at $\mathrm{pH}$ values of $1.5,2.0$, and 2.5 


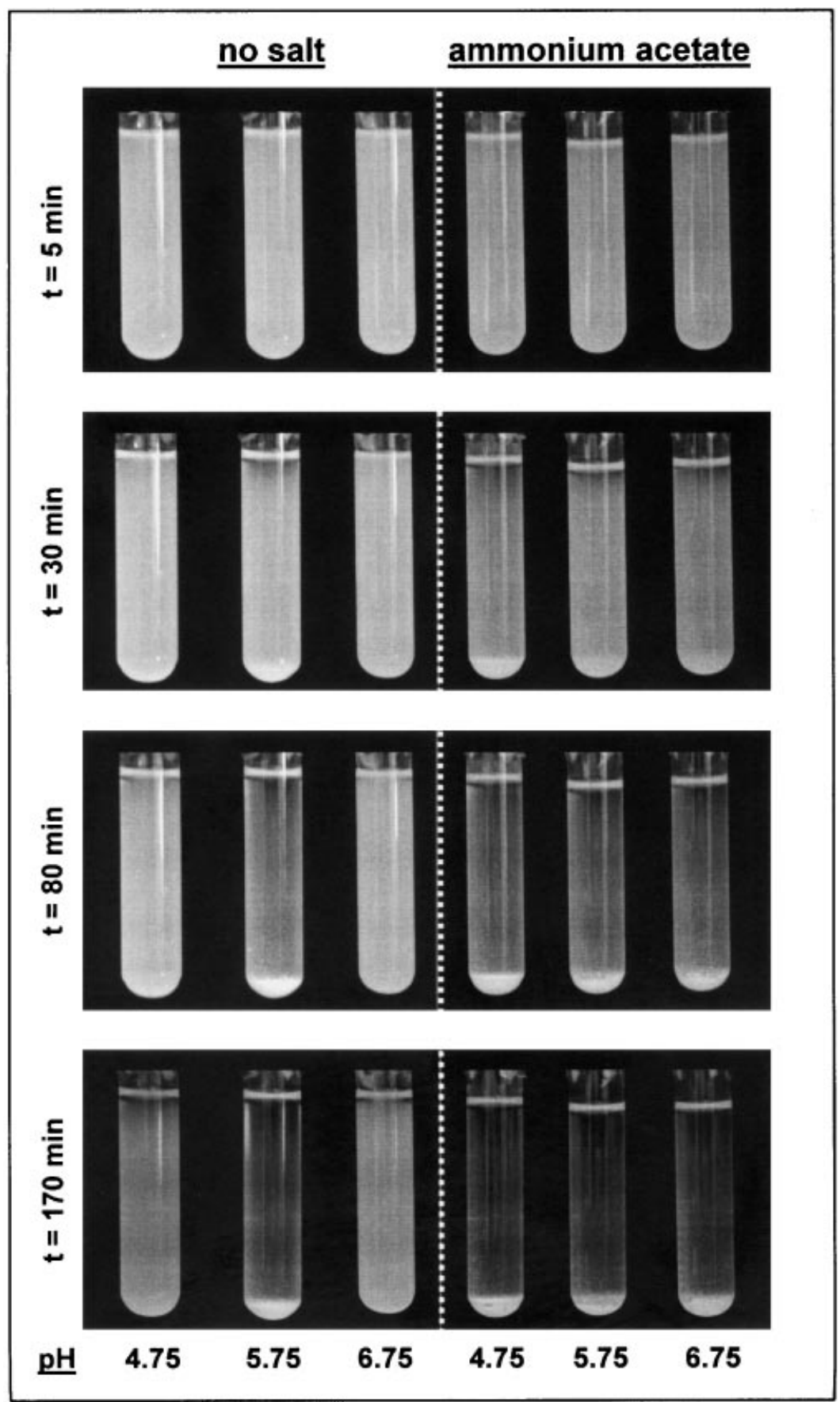

Fig. 4. Sedimentation of silicalite (Sample 3, $\mathrm{Si} / \mathrm{Al}>2000$ ) suspended in $\mathrm{H}_{2} \mathrm{O}$ (left) and aqueous solution of $0.5 \mathrm{M}$ ammonium acetate (right) at $\mathrm{pH}$ values of $4.75,5.75$, and 6.75 
on the right side) enables the formation of larger aggregates of zeolite crystals in a broader $\mathrm{pH}$ range, and the speed of sedimentation is higher. It should be noted that the aggregation is completely reversible. Both, a change of the $\mathrm{pH}$ value or a decrease in ionic strength by dilution, will cause peptization of the particles.

It is obvious from DLVO theory that every other salt apart from ammonium formate or ammonium acetate can serve as a flocculant as well. In view of the application of zeolites in catalysis or adsorption, however, it is desirable to employ salts that can be completely removed. For instance, all types of ammonium salts $\left(\mathrm{R}^{1} \mathrm{R}^{2} \mathrm{R}^{3} \mathrm{R}^{4} \mathrm{~N}^{+}\right.$with $\mathrm{R}$ being a $\mathrm{H}$-atom or an alkyl group) of carboxylic acids are beneficial in this instance, because they can be decomposed and released from the zeolite by means of calcination, which is a typical operation in the conditioning of zeolites. It is also obvious that the destabilizing effect of electrolytes is not restricted to sols and suspensions of MFI-type zeolites. Zeolites of any other structure type can be precipitated in the same manner [7].

Conclusions. - The addition of electrolytes to aqueous zeolite sols promotes the formation of aggregates that are larger than in the absence of these salts, and that can exist in a broader $\mathrm{pH}$ range. While this qualitative behavior could be expected from the DLVO theory, the exact conditions of aggregation cannot be predicted, because zeolites exist in a great variety of different crystal structures and compositions.

The knowledge of both, the specific IEP of a zeolite and the means to trigger its aggregation, are prerequisites for efficient solid-liquid separation. We have shown that the amount of framework aluminium and the accessibility of the pore system are decisive factors for the position of the IEP. For instance, when aluminium is incorporated, and the pores are accessible to the ions in the solution, the IEP of a zeolite is typically found at $\mathrm{pH} c a$. 0 . In this case, aggregation at the IEP is not advisable, because zeolites are unstable at strongly acidic conditions. However, the addition of electrolytes allows for flocculation and facilitated recovery of the zeolite crystals at $\mathrm{pH}>2$.

T. Mäurer thanks Max Buchner-Stiftung for a grant.

\section{REFERENCES}

[1] C. P. Huang, E. A. Rhoads, J. Colloid Interface Sci. 1989, 131, 289.

[2] B. J. Schoeman, J. Sterte, KONA 1997, 15, 150.

[3] W. M. Meier, D. H. Olson, 'Atlas of Zeolite Structure Types', International Zeolite Association - Structure Commission, Butterworth-Heinemann, London, 1992.

[4] T. Mäurer, S. P. Müller, B. Kraushaar-Czarnetzki, Ind. Eng. Chem. Res. 2001, 40, 2573.

[5] J. P. Verduijn, to Exxon Chemical Patents Inc., International Patent Application WO 97/03019, 1997.

[6] Ullmann's Encyclopedia 'Industrial Inorganic Chemicals and Products', Wiley-VCH, Weinheim, 1999, Vol. 6.

[7] B. Kraushaar-Czarnetzki, T. Mäurer, to Universität Karlsruhe (TH), Deutsche Offenlegungsschrift DE $10059520,2001$. 